\title{
Association of TNF-alpha, IL-6 and IL-1 beta gene polymorphisms with polycystic ovary syndrome: a meta-analysis
}

Renyong Guo ${ }^{1 \dagger}$, Ying Zheng ${ }^{2 \dagger}$, Jiezuan Yang ${ }^{3}$ and Nengneng Zheng ${ }^{2 *}$

\begin{abstract}
Background: Several studies on the association of TNF-alpha (-308 G/A), IL-6 (-174 G/C) and IL-1beta (-511 C/T) polymorphisms with polycystic ovary syndrome (PCOS) risk have reported conflicting results. The aim of the present study was to assess these associations by meta-analysis.

Results: A total of 14 eligible articles (1665 cases/1687 controls) were included in this meta-analysis. The results suggested that there was no obvious association between the TNF-alpha (-308 G/A) polymorphism and PCOS in the overall population or subgroup analysis by ethnicity, Hardy-Weinberg equilibrium (HWE) in controls, genotyping method, PCOS diagnosis criteria, and study sample size. Also, no obvious association was found between the TNF-alpha (-308 G/A) polymorphism and obesity in patients with PCOS (body mass index $[\mathrm{BMI}] \geq 25 \mathrm{~kg} / \mathrm{m}^{2} \mathrm{vs}$. $\left.\mathrm{BMl}<25 \mathrm{~kg} / \mathrm{m}^{2}\right)$. Regarding the $/ \mathrm{L}-6(-174 \mathrm{G} / \mathrm{C})$ polymorphism, also no association was found in the overall population in heterozygote comparison, dominant model, and recessive model. Even though an allelic model (odds ratio $[O R]=0.63,95 \%$ confidence interval $[\mathrm{Cl}]=0.41-0.96)$ and a homozygote comparison $(\mathrm{OR}=0.52$, $95 \% \mathrm{Cl}=0.30-0.93)$ showed that the $/ L-6(-174 \mathrm{G} / \mathrm{C})$ polymorphism was marginally associated with PCOS. Further subgroup analysis suggested that the effect size was not significant among HWE in controls (sample size $\leq 200$ ) and genotyping method of pyrosequencing under all genetic models. Similarly, there was no association between the IL-1beta (-511C C T ) polymorphism and PCOS in the overall population or subgroup analysis under all genetic models. Furthermore, no significant association was found between the IL-1beta (-511 C $/ T$ ) polymorphism and several clinical and biochemical parameters in patients with PCOS.
\end{abstract}

Conclusions: The results of this meta-analysis suggest that the TNF-alpha (-308 G/A), IL-6 (-174 G/C), and IL-1beta (-511 C/T) polymorphisms may not be associated with PCOS risk. However, further case-control studies with larger sample sizes are needed to confirm our results.

Keywords: Polycystic ovary syndrome, TNF-alpha, IL-6, IL-1beta, Polymorphism, Meta-analysis

\section{Background}

Polycystic ovary syndrome (PCOS) is a common and complex endocrine disorder leading to reproductive dysfunction in females, with a prevalence of $5 \%-10 \%$ [1]. Hyperandrogenism, oligo/anovulation, polycystic ovaries, hyperinsulinemia, and obesity are main manifestations of PCOS with a subsequent increased risk for type 2 diabetes [2]. Although the etiology of PCOS remains controversial,

\footnotetext{
*Correspondence: Ih_znn@126.com

${ }^{\dagger}$ Equal contributors

${ }^{2}$ Department of Gynecology and Obstetrics, Tongde Hospital of Zhejiang

Province, Hangzhou, Zhejiang 310012, China

Full list of author information is available at the end of the article
}

interactions of hereditary and environmental factors are reportedly associated with PCOS [3].

Recent studies have shown that chronic low grade inflammation is closely related to the incidence of PCOS [4]. Pro-inflammatory cytokines, such as tumor necrosis factor alpha (TNF-alpha), interleukin (IL)-6, and IL-1, are prominent mediators of inflammation and have been confirmed to be elevated in at least a subgroup of women with PCOS [5-7]. The corpus luteum secretes TNF-alpha and the levels of immunoreactive TNF-alpha vary throughout the menstrual cycle [8]. TNF-alpha, IL-6, and IL-1 are presumed to play pivotal roles in reproductive physiology, including regulation of ovarian steroid 
production, follicular maturation, and the processes of ovulation, fertilization, and implantation- parameters all affected in women with PCOS $[9,10]$.

The TNF-alpha gene resides within the class III region of the major histocompatibility complex and is located on the short arm of chromosome 6 (6p21.3). A single nucleotide polymorphism (SNP) located at position -308 in the promoter region of the TNF-alpha gene gives rise to a G-A exchange, which has been associated with elevated serum TNF-alpha concentrations in certain clinical states [5,11]. The human $I L-6$ gene is located at chromosome 7p21-24 and has an upstream 303 bp promoter. A SNP, which results in exchange of G-C at position -174 in the promoter region of the $I L-6$ gene, has been found to influence its transcription rate [12]. The $I L-1$ gene cluster on chromosome 2q12-13 contains three related genes, IL-1alpha, IL-1beta, and IL-1RN. A common C/T SNP of the IL-1beta promoter at position -511 has been found to correspond with altered IL-1beta protein expression both in vitro and in vivo [13].

Recently, a number of research groups have evaluated the usefulness of the TNF-alpha (-308 G/A), IL-6 $(-174 \mathrm{G} / \mathrm{C})$, and IL-1beta $(-511 \mathrm{C} / \mathrm{T})$ polymorphisms as potential susceptibility factors for PCOS. However, the results of published studies are inconclusive and even controversial [7,14-26], which could be due to differences in the studied populations and limited sample sizes. Therefore, in this study, a meta-analysis of 14 eligible articles was performed to clarify these inconsistences and provide more conclusive results.

\section{Methods}

\section{Publication search and inclusion criteria}

To identify all published reports on the association between TNF-alpha (-308 G/A), IL-6 (-174 G/C), and IL-1beta $(-511 \mathrm{C} / \mathrm{T})$ polymorphisms and PCOS risk, we performed a systematic literature search of PubMed, ISI Web of Science, Elsevier Science Direct, China Biology Medical Literature Database, China National Knowledge Infrastructure, and Wanfang online libraries using the terms "polymorphism or variant or mutation" and "polycystic ovary syndrome or PCOS" and "tumor necrosis factor alpha or TNF-alpha or interleukin-6 or IL-6 or interleukin-1beta or IL-1beta" without any language restrictions. We also conducted a manual search of references in the individual articles to identify other potential publications. All clearly irrelevant studies, case reports, editorials, and review articles were excluded. The literature search was updated on September 15, 2014. This meta-analysis was conducted and reported according to the Preferred Reporting Items for Systematic Reviews and Meta-Analysis (PRISMA) Statement [27] (see the checklist included in Additional file 1).

Eligible studies were selected according to the following explicit inclusion criteria: (1) evaluated the association between TNF-alpha (-308 G/A), IL-6 (-174 G/C) and IL-1beta $(-511 \mathrm{C} / \mathrm{T})$ polymorphisms and susceptibility to PCOS; (2) case-control studies based on unrelated individuals; (3) all patients met the diagnostic criteria for PCOS; (4) must provide sufficient genotype data to calculate odds ratios (ORs) and 95\% confidence intervals (CIs). Articles that did not meet our inclusion criteria were excluded. When a study reported the results on different ethnicities, we treated them independently.

\section{Data extraction}

Two authors independently extracted all data based on the inclusion criteria listed above. Any disagreement was subsequently resolved by consensus with a third author. The following items were collected from each study: the first author's name, year of publication, source of publication, ethnicity of the population, sample size, PCOS diagnostic criteria, genotyping method, genotype frequencies, and probability $(p)$ value for the Hardy-Weinberg equilibrium (HWE) in controls. If original genotype frequency data were unavailable in relevant articles, a request for additional data was sent to the corresponding author.

\section{Quality assessment}

Two reviewers independently assessed the quality of every included study according to the Newcastle-Ottawa Scale (NOS) (www.ohri.ca/programs/clinical_epidemiology/oxford. asp). This scale contains nine items (1 point for each) in three parts relating to selection, comparability and ascertainment of exposure. A score of five or more was defined as having high quality; otherwise, the study was regarded as "low quality" [28].

\section{Statistical analysis}

Crude ORs with 95\% CIs were used to assess the association between TNF-alpha (-308 G/A), IL-6 (-174 G/C) and IL-1beta $(-511 \mathrm{C} / \mathrm{T})$ polymorphisms with PCOS risk. Analysis of polymorphisms was conducted in at least two studies. The pooled OR was calculated for the allele model, homozygote comparison, heterozygote comparison, dominant model, and recessive model. The $\mathrm{Z}$ test was used to estimate the statistical significance of pooled ORs and a $p$-value $<0.05$ was considered statistically significant. Genotype frequencies of healthy controls were tested for HWE using the $\chi^{2}$ test. The Cochran Q test and $\mathrm{I}^{2}$ test were used to evaluate potential heterogeneity between studies. Significant heterogeneity was indicated by $p<0.10$ for the Q test or $\mathrm{I}^{2}$ test of $>50 \%$ [29]. The pooled ORs were analyzed using the random effects model [30]. Otherwise, the fixed effects model [31] was selected. Subgroup analyses were conducted to explore reasons for heterogeneity. In order to evaluate the influence of single studies on the overall estimate, sensitivity analysis was performed. Potential publication bias was diagnosed 
statistically via the Begg's test and Egger's test. The presence of publication bias was indicated by a $p$-value $<0.05$ $[32,33]$. Data management and analysis were performed using STATA statistical software (version 12.0; Stata Corporation, College Station, TX, USA).

\section{Results}

\section{Characteristics of included studies}

The literature search identified a total of 326 potentially relevant papers. There were 272 potentially relevant papers after duplicates were removed. After review of the titles and abstracts of all articles, 242 were excluded; full texts were also reviewed and 16 articles were further excluded. Finally, a total of 14 eligible articles with a total of 1665 PCOS patients and 1687 healthy subjects met the inclusion criteria and were included in this metaanalysis [7,14-26], with one study that included both TNF-alpha (-308 G/A) and IL-6 (-174 G/C) polymorphisms [22]. The flow chart in Figure 1 is a summary of the literature review process. Study characteristics are summarized in Table 1. Overall, six studies were conducted among Caucasians and eight among Asians. The Rotterdam diagnostic criteria were used in 12 studies and the NIH criteria in two. In 8 of 14 studies, DNA was extracted from peripheral blood and analyzed with a classic polymerase chain reaction-restriction fragment length polymorphism (PCR-RFLP) assay. The NOS results showed that the median overall score was 6 (range, 4-8). Thirteen studies were considered high quality and one as low quality. In addition, four studies reported a deviation of the genotype distributions among the controls from the HWE $[17,21,23,25]$.

\section{Meta-analysis results}

A total of 802 cases and 802 controls were assessed to identify associations between the TNF-alpha (-308 G/A) polymorphism and PCOS. The A allele was considered as the risk variant. However, we found no association between the TNF-alpha (-308 G/A) polymorphism and PCOS risk in the overall population (A vs. G: $\mathrm{OR}=0.93$,

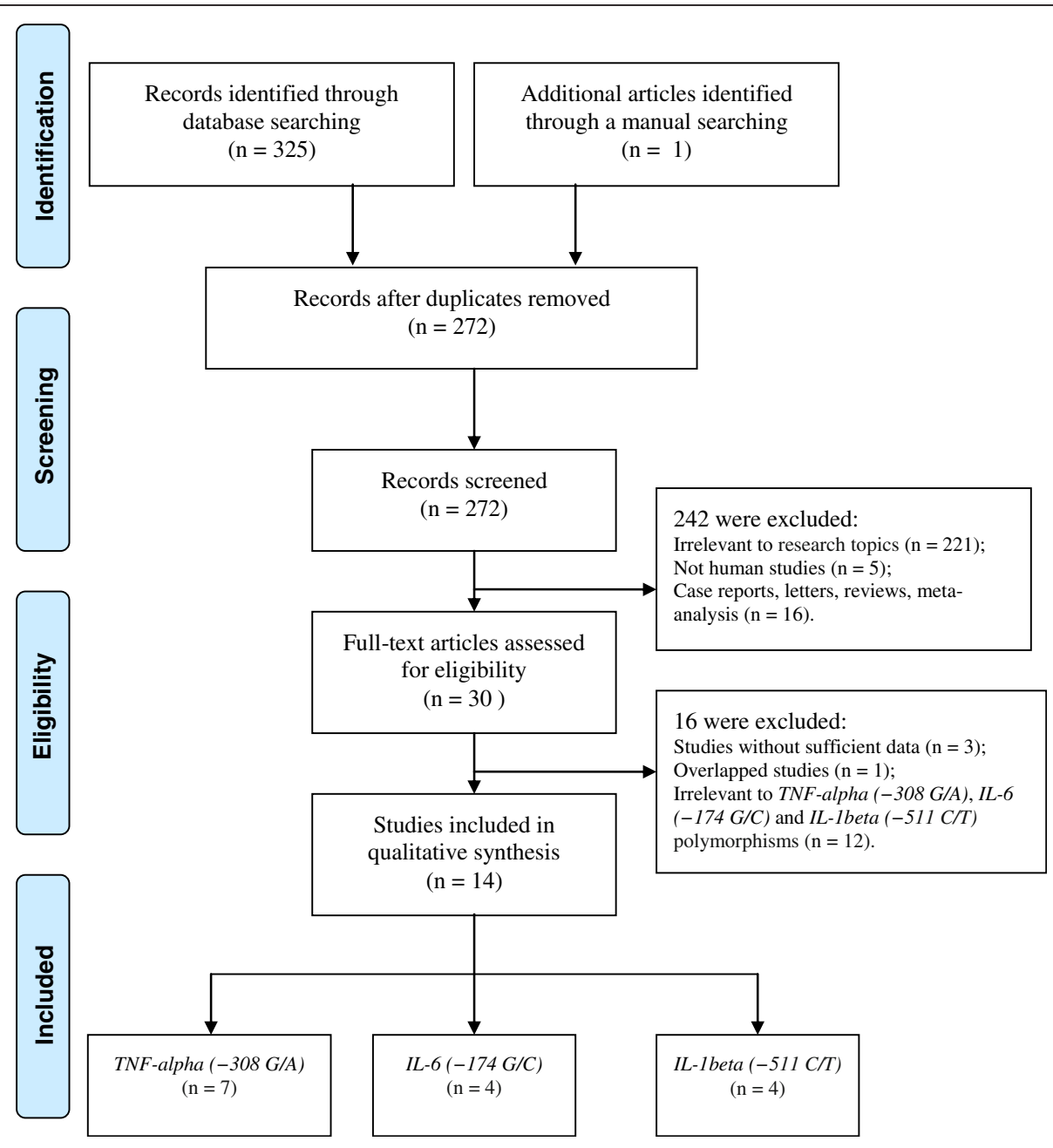

Figure 1 Flow diagram of the study selection process. 
Table 1 Characteristic of the studies included in this meta-analysis

\begin{tabular}{|c|c|c|c|c|c|c|c|c|c|c|c|c|c|c|}
\hline \multirow[t]{2}{*}{ Study name } & \multirow[t]{2}{*}{ Year } & \multirow[t]{2}{*}{ Country } & \multirow[t]{2}{*}{ Ethnicity } & \multicolumn{2}{|c|}{ Age, years, mean $\pm S D$} & \multicolumn{2}{|c|}{ Sample size } & \multirow{2}{*}{$\begin{array}{l}\text { PCOS diagnostic } \\
\text { criteria }\end{array}$} & \multirow{2}{*}{$\begin{array}{l}\text { Genotyping } \\
\text { method }\end{array}$} & \multirow{2}{*}{$\begin{array}{l}\text { NOS } \\
\text { score }\end{array}$} & \multicolumn{3}{|c|}{ Genotype (case/control) } & \multirow[t]{2}{*}{$P_{\mathrm{HWE}}{ }^{\mathrm{b}}$} \\
\hline & & & & Cases & Controls & Cases & Controls & & & & 11 & 12 & 22 & \\
\hline \multicolumn{15}{|c|}{ TNF-alpha (-308 G/A) } \\
\hline Milner et al. [14] & 1999 & Australia & Caucasian & NA & NA & 84 & 108 & $\mathrm{NIH}$ criteria & PCR-SSCP & 4 & $59 / 63$ & $23 / 42$ & $2 / 3$ & 0.194 \\
\hline Mao et al. [15] & 2000 & China & Asian & $28.0 \pm 0.5$ & $31.1 \pm 1.1$ & 118 & 54 & $\mathrm{NIH}$ criteria & PCR-RFLP & 6 & $88 / 37$ & 29/13 & $1 / 4$ & 0.089 \\
\hline Vural et al. [22] & 2010 & Turkey & Caucasian & $25(17-39)^{a}$ & $27(18-39)^{a}$ & 97 & 95 & Rotterdam criteria & PCR-RFLP & 8 & $78 / 77$ & $16 / 15$ & $3 / 3$ & 0.055 \\
\hline Zhang et al. [16] & 2010 & China & Asian & $29.0 \pm 1.5$ & $30.0 \pm 1.5$ & 78 & 40 & Rotterdam criteria & Microarray & 7 & $72 / 36$ & $6 / 4$ & $0 / 0$ & 0.739 \\
\hline Deepika et al. [17] & 2013 & India & Asian & NA & NA & 283 & 306 & Rotterdam criteria & ARMS PCR & 6 & $10 / 10$ & $270 / 293$ & $3 / 3$ & $<0.05$ \\
\hline Wen et al. [18] & 2013 & China & Asian & $26.86 \pm 4.5$ & $27.3 \pm 3.71$ & 103 & 59 & Rotterdam criteria & PCR-RFLP & 8 & $89 / 52$ & $14 / 7$ & $0 / 0$ & 0.628 \\
\hline Grech et al. [19] & 2014 & Greece & Caucasian & $22.5 \pm 3.2$ & NA & 39 & 140 & Rotterdam criteria & PCR-RFLP & 5 & $33 / 125$ & $6 / 14$ & $0 / 1$ & 0.394 \\
\hline \multicolumn{15}{|l|}{ IL-6 (-174 G/C) } \\
\hline Walch et al. [20] & 2004 & Austria & Caucasian & $28(20-39)^{a}$ & NA & 62 & 94 & Rotterdam criteria & Pyrosequencing & 6 & $24 / 43$ & $30 / 35$ & $8 / 16$ & 0.068 \\
\hline Erdogan et al. [21] & 2009 & Turkey & Caucasian & $24.07 \pm 1.32$ & $25.01 \pm 2.05$ & 88 & 119 & Rotterdam criteria & PCR-RFLP & 8 & $57 / 32$ & $26 / 75$ & $5 / 12$ & $<0.05$ \\
\hline Vural et al. [22] & 2010 & Turkey & Caucasian & $25(17-39)^{a}$ & $27(18-39)^{a}$ & 97 & 95 & Rotterdam criteria & PCR-RFLP & 8 & $59 / 46$ & $34 / 42$ & $4 / 7$ & 0.536 \\
\hline Tumu et al. [23] & 2013 & India & Asian & $26.35 \pm 3.88$ & $30.00 \pm 5.17$ & 104 & 156 & Rotterdam criteria & Pyrosequencing & 6 & $69 / 77$ & $31 / 73$ & $4 / 6$ & $<0.05$ \\
\hline \multicolumn{15}{|l|}{ IL-1beta (-511 C/T) } \\
\hline Kolbus et al. [24] & 2007 & Austria & Caucasian & $27.9 \pm 5.0$ & $28.8 \pm 5.9$ & 105 & 102 & Rotterdam criteria & Pyrosequencing & 7 & $43 / 40$ & $47 / 48$ & $15 / 14$ & 0.947 \\
\hline Yang et al. [25] & 2009 & China & Asian & NA & NA & 118 & 86 & Rotterdam criteria & PCR-RFLP & 5 & $30 / 34$ & $56 / 26$ & $32 / 26$ & $<0.05$ \\
\hline Mu et al. [26] & 2010 & China & Asian & $26.91 \pm 4.02$ & $31.14 \pm 4.22$ & 200 & 177 & Rotterdam criteria & PCR-RFLP & 6 & $64 / 26$ & $76 / 87$ & $60 / 64$ & 0.684 \\
\hline Xia et al. [7] & 2013 & China & Asian & $29.75 \pm 3.62$ & $28.93 \pm 3.91$ & 59 & 56 & Rotterdam criteria & PCR-RFLP & 6 & $13 / 18$ & $21 / 31$ & $25 / 7$ & 0.257 \\
\hline
\end{tabular}

For TNF-alpha $(-308 \mathrm{G} / \mathrm{A}), 11=\mathrm{GG}, 12=\mathrm{GA}, 22=\mathrm{AA}$; For $\mathrm{LL}-6(-174 \mathrm{G} / \mathrm{C}), 11=\mathrm{GG}, 12=\mathrm{GC}, 22=\mathrm{CC}$; For $1 \mathrm{l}-1$ beta $(-511 \mathrm{CT}), 11=\mathrm{CC}, 12=\mathrm{CT}, 22=\mathrm{T}$.

NA, not available; HWE, Hardy-Weinberg equilibrium; PCR-RFLP, polymerase chain reaction-restriction fragment length polymorphism; SSCP, single-strand conformational polymorphism; ARMS, amplification refractory mutation system; NOS, Newcastle-Ottawa Scale; ${ }^{a}$ values are given as median (range); ${ }^{b} p$ value for HWE in controls. 
Table 2 Meta-analysis of TNF-alpha (-308 G/A) polymorphism and PCOS risk

\begin{tabular}{|c|c|c|c|c|c|c|c|c|c|c|c|}
\hline \multirow[t]{2}{*}{ Comparison } & \multirow{2}{*}{$\begin{array}{l}\text { No. of } \\
\text { studies }\end{array}$} & \multicolumn{2}{|l|}{ A vs. G } & \multicolumn{2}{|l|}{$A A$ vs. $G^{a}$} & \multicolumn{2}{|l|}{ GA vs. GG } & \multicolumn{2}{|l|}{$A A+G A$ vs. $G G$} & \multicolumn{2}{|l|}{$A A$ vs. $G A+G^{a}$} \\
\hline & & OR $(95 \% \mathrm{Cl})$ & $P_{\mathrm{H}}$ & OR $(95 \% \mathrm{Cl})$ & $P_{\mathrm{H}}$ & OR $(95 \% \mathrm{Cl})$ & $P_{\mathrm{H}}$ & OR $(95 \% \mathrm{Cl})$ & $P_{\mathrm{H}}$ & OR $(95 \% \mathrm{Cl})$ & $P_{\mathrm{H}}$ \\
\hline Overall & 7 & $0.93(0.77-1.11)^{F}$ & 0.610 & $0.61(0.26-1.41)^{F}$ & 0.519 & $0.89(0.65-1.23)^{F}$ & 0.725 & $0.85(0.63-1.16)^{F}$ & 0.741 & $0.66(0.29-1.49)^{F}$ & 0.495 \\
\hline $\begin{array}{l}\text { HWE in controls/ } \\
\text { sample size } \leq 200\end{array}$ & 6 & $0.82(0.61-1.10)^{F}$ & 0.634 & $0.53(0.20-1.39)^{F}$ & 0.397 & $0.89(0.63-1.25)^{F}$ & 0.603 & $0.84(0.61-1.17)^{F}$ & 0.625 & $0.55(0.21-1.44)^{F}$ & 0.389 \\
\hline PCR-RFLP & 4 & $0.91(0.63-1.32)^{F}$ & 0.469 & $0.47(0.15-1.47)^{F}$ & 0.236 & $1.11(0.72-1.71)^{F}$ & 0.864 & $1.00(0.67-1.52)^{F}$ & 0.699 & $0.47(0.15-1.46)^{F}$ & 0.245 \\
\hline \multicolumn{12}{|l|}{ Ethnicity } \\
\hline Asian & 4 & $0.95(0.77-1.16)^{\mathrm{F}}$ & 0.523 & $0.37(0.10-1.36)^{F}$ & 0.124 & $0.96(0.60-1.52)^{F}$ & 0.960 & $0.87(0.55-1.37)^{\mathrm{F}}$ & 0.893 & $0.39(0.04-3.72)^{R}$ & 0.096 \\
\hline Caucasian & 3 & $0.86(0.59-1.24)^{F}$ & 0.354 & $0.89(0.29-2.78)^{F}$ & 0.944 & $0.84(0.54-1.30)^{F}$ & 0.201 & $0.84(0.55-1.28)^{F}$ & 0.234 & $0.95(0.31-2.95)^{F}$ & 0.98 \\
\hline \multicolumn{12}{|l|}{$\begin{array}{l}\text { PCOS diagnostic } \\
\text { criteria }\end{array}$} \\
\hline $\mathrm{NIH}$ criteria & 2 & $0.65(0.44-1.02)^{F}$ & 0.869 & $0.31(0.08-1.19)^{F}$ & 0.192 & $0.71(0.44-1.13)^{F}$ & 0.345 & $0.65(0.41-1.03)^{F}$ & 0.638 & $0.35(0.09-1.30)^{F}$ & 0.154 \\
\hline Rotterdam criteria & 5 & $1.01(0.83-1.24)^{F}$ & 0.955 & $1.02(0.33-3.19)^{F}$ & 0.991 & $1.08(0.70-1.66)^{F}$ & 0.903 & $1.06(0.70-1.62)^{F}$ & 0.930 & $1.05(0.36-3.07)^{F}$ & 0.99 \\
\hline
\end{tabular}

$\mathrm{OR}$, odds ratio; $\mathrm{Cl}$, confidence interval; No., number; vs.: versus; $P_{\mathrm{H}}, p$ value of Q-test for heterogeneity test; ${ }^{\mathrm{R}}$ random-effect model; ${ }^{\mathrm{F}}$ fixed-effect model.

athe studies by Zhang et al. and Wen et al. were not included since they presented 0 frequency of AA genotype in cases and controls.

95\% CI $=0.77-1.11 ;$ AA vs. GG: $\mathrm{OR}=0.61,95 \% \mathrm{CI}=$ $0.26-1.41$; GA vs. GG: OR $=0.89,95 \% \mathrm{CI}=0.65-1.23$; $\mathrm{AA}+\mathrm{GA}$ vs. $\mathrm{GG}: \mathrm{OR}=0.85,95 \% \mathrm{CI}=0.63-1.16$; $\mathrm{AA}$ vs. $\mathrm{GA}+\mathrm{GG}: \mathrm{OR}=0.66,95 \% \mathrm{CI}=0.29-1.49)$. After performing stratified analysis for HWE in controls, sample size $\leq 200$, PCR-RFLP, PCOS diagnosis criteria, and ethnicity separately, the association remained non-significant (Table 2, Figure 2). In addition, data on genotype distributions of the TNF-alpha (-308 G/A) polymorphism in PCOS patients with a body mass index $(B M I) \geq 25 \mathrm{~kg} / \mathrm{m}^{2}$ and $\mathrm{BMI}<25 \mathrm{~kg} / \mathrm{m}^{2}$ were available in three studies [15-17]. The results showed no significant association of the TNF-alpha (-308 G/A) polymorphism with obesity in patients with $\operatorname{PCOS}\left(\mathrm{BMI} \geq 25 \mathrm{~kg} / \mathrm{m}^{2}\right.$ vs. $\left.\mathrm{BMI}<25 \mathrm{~kg} / \mathrm{m}^{2}\right)$ (AA + GA vs. GG: OR = 0.94, 95\% CI =0.49-1.79; Figure 3).

Four studies (351 cases and 464 controls) investigated the association of the $I L-6(-174 \mathrm{G} / \mathrm{C})$ polymorphism with PCOS risk and were included in the analysis. Overall, no obvious associations were found by heterozygote comparison (GC vs. GG: OR $=0.54,95 \% \mathrm{CI}=0.25-1.17$ ) or in the dominant model $(\mathrm{CC}+\mathrm{GC}$ vs. $\mathrm{GG}$ : $\mathrm{OR}=0.53$, 95\% CI $=0.26-1.08)$ and recessive models (CC vs. $\mathrm{GC}+$ GG: $\mathrm{OR}=0.67,95 \% \mathrm{CI}=0.39-1.16)$ (Table 3, Figure 4). However, the results indicated that the $I L-6(-174 \mathrm{G} / \mathrm{C})$ polymorphism was marginally associated with PCOS in the allelic model ( $\mathrm{C}$ vs. $\mathrm{G}$ : $\mathrm{OR}=0.63,95 \% \mathrm{CI}=0.41-$

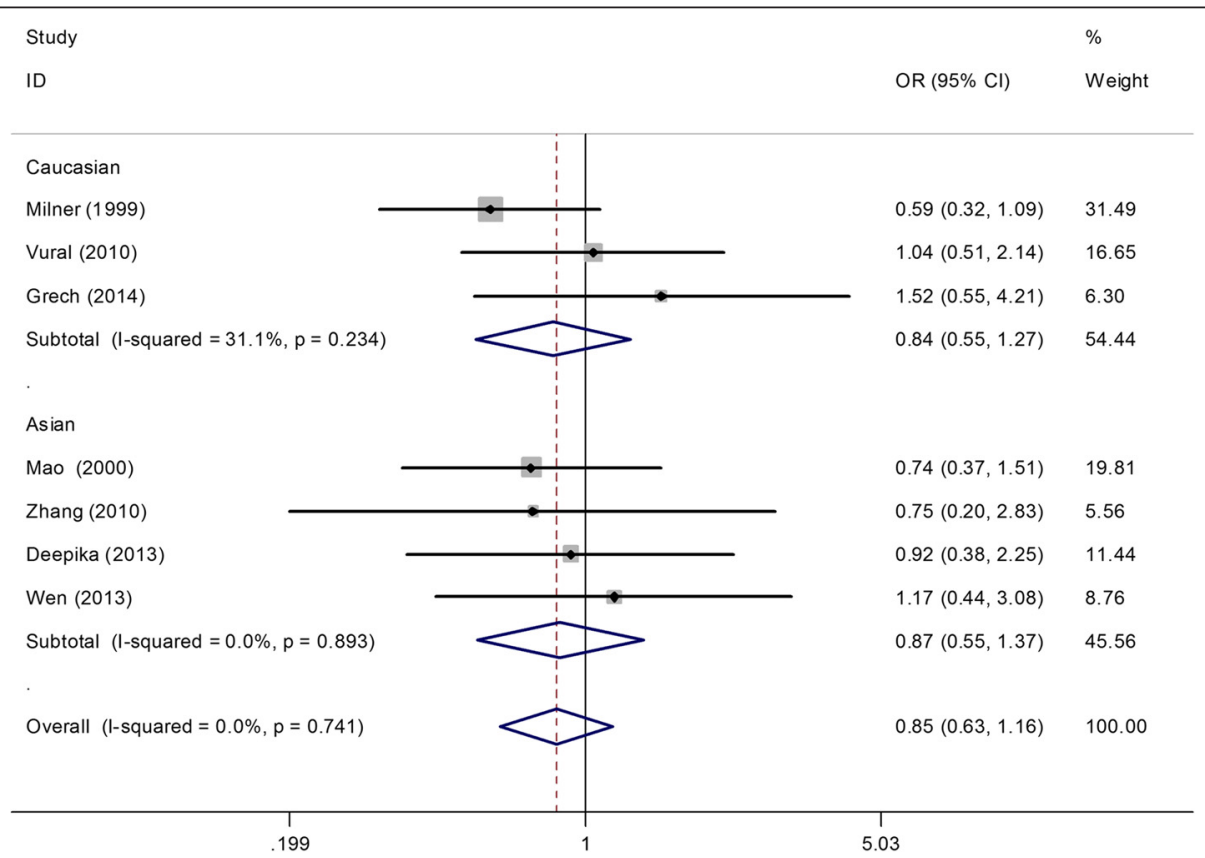

Figure 2 Meta-analysis for the association between the TNF-alpha (-308 G/A) polymorphism and risk of polycystic ovary syndrome based on the dominant model ( $A A+G A$ vs. GG; stratified by ethnicity). 


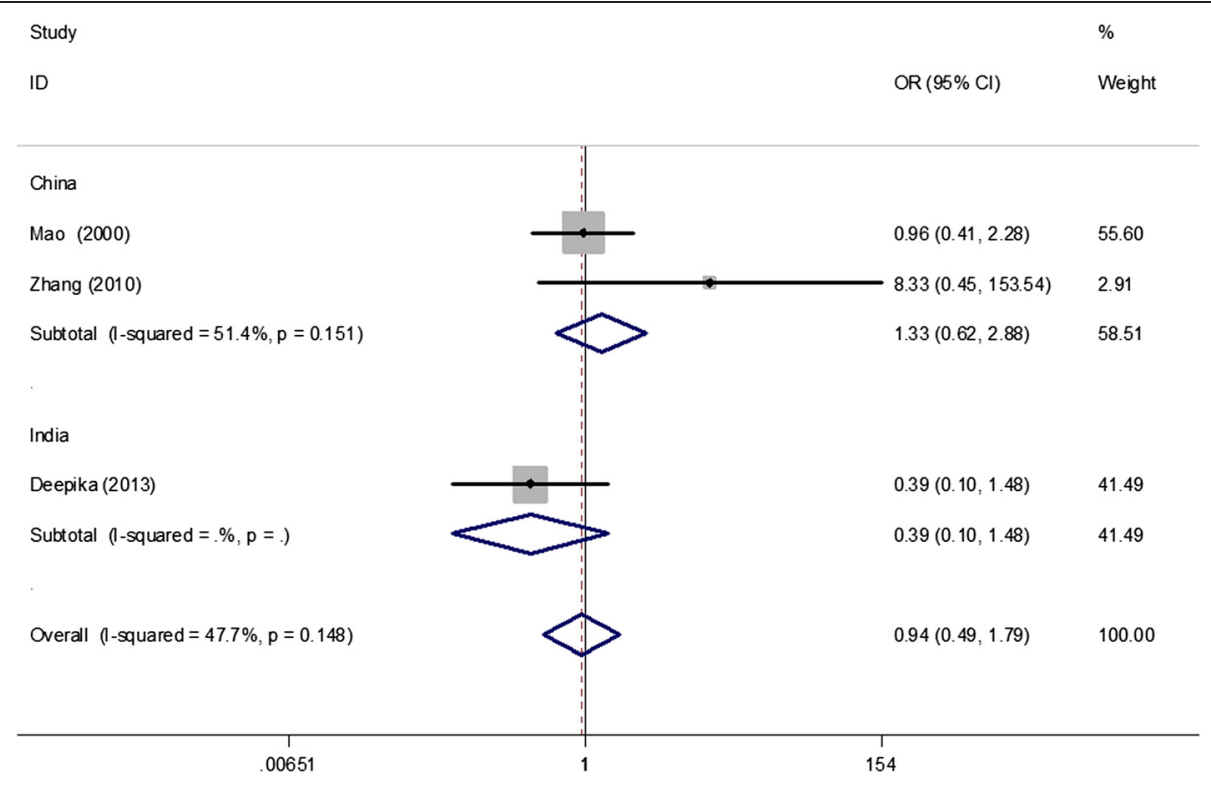

Figure 3 A forest plot for the correlation of the TNF-alpha $(-308 \mathrm{G} / \mathrm{A})$ polymorphism with obesity in patients with polycystic ovary syndrome $\left(B M I \geq 25 \mathrm{~kg} / \mathrm{m}^{2}\right.$ vs. BMI $<25 \mathrm{~kg} / \mathrm{m}^{2}$ ) based on the dominant model (AA + GA vs. GG; stratified by country).

0.96) and by homozygote comparison (CC vs. GG: OR = $0.52,95 \% \mathrm{CI}=0.30-0.93)$. In further subgroup analysis based on study sample size, the IL-6 (-174 G/C) polymorphism was significantly associated with a decreased PCOS risk among sample size $>200$ in the allelic model (C vs. $\mathrm{G}: \mathrm{OR}=0.47,95 \% \mathrm{CI}=0.28-0.80)$ and dominant model (CC + GC vs. GG: $\mathrm{OR}=0.32,95 \% \mathrm{CI}=0.13-0.78)$, as well as by homozygote comparison (CC vs. GG: OR = $0.38,95 \% \mathrm{CI}=0.17-0.89$ ) and heterozygote comparison (GC vs. GG: $\mathrm{OR}=0.31,95 \% \mathrm{CI}=0.13-0.74)$. Stratification by the genotyping method indicated that the examined SNP was associated with a decreased risk of PCOS among genotyping method of PCR-RFLP in the allelic model (C vs. $\mathrm{G}$ : $\mathrm{OR}=0.49,95 \% \mathrm{CI}=0.27-0.88)$ and by homozygote comparison (CC vs. GG: $\mathrm{OR}=0.31,95 \% \mathrm{CI}=0.13-0.72$ ). Even so, the effect size was not significant among HWE in controls (sample size $\leq 200$ ) and genotyping method of pyrosequencing under all genetic models.

Under all genetic models, no obvious associations were found between the IL-1beta $(-511 \mathrm{C} / \mathrm{T})$ polymorphism and PCOS risk when all studies were pooled into the meta-analysis ( $\mathrm{T}$ vs. $\mathrm{C}$ : $\mathrm{OR}=1.11,95 \% \mathrm{CI}=0.67-1.84$; TT vs. CC: $\mathrm{OR}=0.89,95 \% \mathrm{CI}=0.62-1.27$; $\mathrm{TC}$ vs. $\mathrm{CC}$ : $\mathrm{OR}=0.91,95 \% \mathrm{CI}=0.40-2.11 ; \mathrm{TT}+\mathrm{CT}$ vs. $\mathrm{CC}: \mathrm{OR}=$ 1.0, 95\% CI = 0.45-2.19; TT vs. CT + CC: OR $=1.26,95 \%$ $\mathrm{CI}=0.62-2.53)$. In the subgroup analysis by ethnicity, HWE in controls, genotyping method, and study sample size, still no obvious associations were found (Table 4, Figure 5). Additionally, two studies [24,26] provided data between the $I L-1$ beta $(-511 \mathrm{C} / \mathrm{T})$ polymorphism and several clinical and biochemical parameters in patients with PCOS. The results showed no significant association of

Table 3 Meta-analysis of IL-6 (-174 G/C) polymorphism and PCOS risk

\begin{tabular}{|c|c|c|c|c|c|c|c|c|c|c|c|}
\hline \multirow[t]{2}{*}{ Comparison } & \multirow{2}{*}{$\begin{array}{l}\text { No. of } \\
\text { studies }\end{array}$} & \multicolumn{2}{|l|}{ C vs. G } & \multicolumn{2}{|l|}{ CC vs. GG } & \multicolumn{2}{|l|}{ GC vs. GG } & \multicolumn{2}{|l|}{ CC + GC vs. GG } & \multicolumn{2}{|l|}{ CC vs. GC + GG } \\
\hline & & OR $(95 \% \mathrm{Cl})$ & $P_{\mathrm{H}}$ & OR $(95 \% \mathrm{Cl})$ & $P_{\mathrm{H}}$ & OR $(95 \% \mathrm{Cl})$ & $P_{\mathrm{H}}$ & OR $(95 \% \mathrm{Cl})$ & $P_{\mathrm{H}}$ & OR $(95 \% \mathrm{Cl})$ & $P_{\mathrm{H}}$ \\
\hline Overall & 4 & $0.63(0.41-0.96)^{R}$ & 0.013 & $0.52(0.30-0.93)^{F}$ & 0.329 & $0.54(0.25-1.17)^{R}$ & $<0.01$ & $0.53(0.26-1.08)^{R}$ & $<0.01$ & $0.67(0.39-1.16)^{F}$ & 0.881 \\
\hline $\begin{array}{l}\text { HWE in controls/ } \\
\text { sample size } \leq 200\end{array}$ & 2 & $0.84(0.60-1.16)^{F}$ & 0.157 & $0.69(0.32-1.50)^{F}$ & 0.398 & $0.97(0.40-2.31)^{R}$ & 0.057 & $0.88(0.41-1.92)^{R}$ & 0.074 & $0.65(0.31-1.37)^{F}$ & 0.716 \\
\hline Sample size $>200^{a}$ & 2 & $0.47(0.28-0.80)^{R}$ & 0.091 & $0.38(0.17-0.89)^{F}$ & 0.189 & $0.31(0.13-0.74)^{R}$ & 0.033 & $0.32(0.13-0.78)^{R}$ & 0.074 & $0.69(0.30-1.59)^{F}$ & 0.469 \\
\hline Caucasian & 3 & $0.63(0.34-1.17)^{R}$ & $<0.01$ & $0.48(0.26-0.91)^{F}$ & 0.211 & $0.57(0.18-1.78)^{R}$ & $<0.01$ & $0.54(0.19-1.55)^{R}$ & $<0.01$ & $0.61(0.33-1.13)^{F}$ & 0.897 \\
\hline \multicolumn{12}{|l|}{$\begin{array}{l}\text { Genotyping } \\
\text { method }\end{array}$} \\
\hline PCR-RFLP & 2 & $0.49(0.27-0.88)^{R}$ & 0.065 & $0.31(0.13-0.72)^{F}$ & 0.461 & $0.35(0.11-1.11)^{R}$ & $<0.01$ & $0.35(0.12-1.03)^{R}$ & $<0.01$ & $0.54(0.24-1.23)^{F}$ & 0.994 \\
\hline Pyrosequencing & 2 & $0.80(0.47-1.37)^{R}$ & 0.092 & $0.84(0.38-1.84)^{F}$ & 0.824 & $0.83(0.26-2.64)^{R}$ & $<0.01$ & $0.80(0.30-2.10)^{R}$ & 0.019 & $0.81(0.38-1.70)^{F}$ & 0.687 \\
\hline
\end{tabular}

OR, odds ratio; $\mathrm{Cl}$, confidence interval; No., number; vs.: versus; $P_{\mathrm{H}}, p$ value of Q-test for heterogeneity test; ${ }^{\mathrm{R}}$ random-effect model; ${ }^{\mathrm{F}}$ fixed-effect model; ${ }^{\mathrm{a}}$ deviated from HWE in controls. 


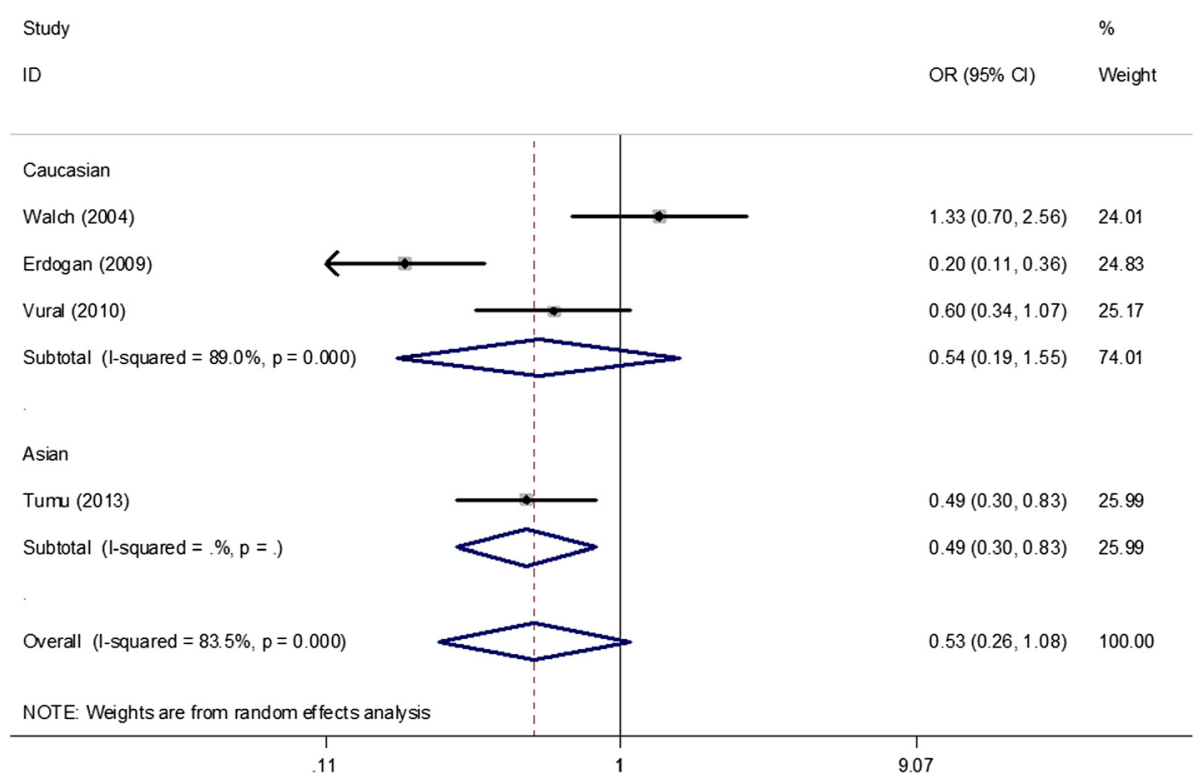

Figure 4 Meta-analysis for the association between the $I L-6(-174 \mathrm{G} / \mathrm{C})$ polymorphism and the risk of polycystic ovary syndrome based on the dominant model (CC + GC vs. GG; stratified by ethnicity).

the IL-1beta $(-511 \mathrm{C} / \mathrm{T})$ polymorphism (TT + CT vs. CC) with menarche age $(\mathrm{SMD}=-0.01,95 \% \mathrm{CI}=-0.25-0.22)$, BMI (SMD $=0.04,95 \% \mathrm{CI}=-0.20-0.27)$, and levels of luteinizing hormone $(\mathrm{LH})(\mathrm{SMD}=-0.00,95 \% \mathrm{CI}=-0.24-$ $0.23)$, follicle-stimulating hormone $(\mathrm{FSH})(\mathrm{SMD}=-0.08$, $95 \% \mathrm{CI}=-0.32-0.16)$, total testosterone (SMD $=0.23$, $95 \% \mathrm{CI}=-0.01-0.47)$ and $\mathrm{LH} / \mathrm{FSH}(\mathrm{SMD}=0.05,95 \%$ $\mathrm{CI}=-0.19-0.28$ ) in patients with PCOS (Figure 6).

\section{Heterogeneity test and sensitivity analysis}

Regarding the TNF-alpha (-308 G/A) polymorphism and PCOS, there was no heterogeneity among studies in overall comparisons $(p>0.10)$. For the $I L-6(-174 \mathrm{G} / \mathrm{C})$ and IL-1beta $(-511 \mathrm{C} / \mathrm{T})$ polymorphisms and PCOS, there was statistical significance with between-study heterogeneity $(p<0.10)$. To explore sources of heterogeneity across studies, subgroup analyses by ethnicity, HWE in controls, genotyping method, and study sample size were conducted. However, none of these variables could explain the heterogeneity. To evaluate the stability of the results of the meta-analysis, sensitivity analyses of the omitted individual studies were performed sequentially. This procedure confirmed that our results were reliable and robust (Figure 7).

\section{Publication bias}

Publication bias was assessed by both the Begg's test and Egger's test. The statistical results did not show any evidence of publication bias $(p>0.05)$, with the exception of the IL-1beta $(-511 \mathrm{C} / \mathrm{T})$ polymorphism under the allelic model with the Egger's test ( $p=0.023$, Table 5$)$. Sensitivity analysis using the trim and fill method was then performed to assess the possibility of publication bias. However, no trimming was performed and the data were unchanged throughout the filled meta-analysis, which suggested the absence of publication bias for the IL-1beta $(-511 \mathrm{C} / \mathrm{T})$ polymorphism under the allelic model.

\section{Discussion}

It is well known that PCOS is a proinflammatory state and chronic low-grade inflammation was found to promote the development of metabolic disruption and ovarian

Table 4 Meta-analysis of IL-1beta $(-511 \mathrm{C} / \mathrm{T})$ polymorphism and PCOS risk

\begin{tabular}{|c|c|c|c|c|c|c|c|c|c|c|c|}
\hline \multirow[t]{2}{*}{ Comparison } & \multirow{2}{*}{$\begin{array}{l}\text { No. of } \\
\text { studies }\end{array}$} & \multicolumn{2}{|l|}{ T vs. C } & \multicolumn{2}{|l|}{ TT vs. CC } & \multicolumn{2}{|l|}{ TC vs. CC } & \multicolumn{2}{|l|}{$\mathrm{TT}+\mathrm{CT}$ vs. CC } & \multicolumn{2}{|l|}{ TT vs. $C T+C C$} \\
\hline & & OR $(95 \% \mathrm{Cl})$ & $P_{\mathrm{H}}$ & OR $(95 \% \mathrm{Cl})$ & $P_{\mathrm{H}}$ & OR $(95 \% \mathrm{Cl})$ & $P_{\mathrm{H}}$ & OR $(95 \% \mathrm{Cl})$ & $P_{\mathrm{H}}$ & OR $(95 \% \mathrm{Cl})$ & $P_{\mathrm{H}}$ \\
\hline Overall & 4 & $1.11(0.67-1.84)^{R}$ & $<0.01$ & $0.89(0.62-1.27)^{R}$ & $<0.01$ & $0.91(0.40-2.11)^{R}$ & $<0.01$ & $1.00(0.45-2.19)^{\mathrm{R}}$ & $<0.01$ & $1.26(0.62-2.53)^{R}$ & $<0.01$ \\
\hline HWE in controls & 3 & $1.08(0.54-2.14)^{R}$ & $<0.01$ & $1.16(0.29-4.61)^{R}$ & $<0.01$ & $0.65(0.33-1.28)^{R}$ & 0.041 & $0.79(0.34-1.86)^{R}$ & $<0.01$ & $1.50(0.53-4.25)^{R}$ & $<0.01$ \\
\hline Asian/PCR-RFLP & 3 & $1.17(0.57-2.42)^{R}$ & $<0.01$ & $1.29(0.33-5.09)^{R}$ & $<0.01$ & $0.92(0.27-3.18)^{R}$ & $<0.01$ & $1.03(0.32-3.30)^{R}$ & $<0.01$ & $1.37(0.53-3.54)^{R}$ & $<0.01$ \\
\hline $\begin{array}{l}\text { Sample } \\
\text { size }>200\end{array}$ & 3 & $0.90(0.58-1.37)^{R}$ & 0.014 & $0.70(0.47-1.03)^{R}$ & 0.014 & $0.91(0.31-2.67)^{R}$ & $<0.01$ & $0.86(0.33-2.21)^{R}$ & $<0.01$ & $0.83(0.60-1.14)^{F}$ & 0.769 \\
\hline
\end{tabular}

$\mathrm{OR}$, odds ratio; $\mathrm{Cl}$, confidence interval; No., number; vs.: versus; $P_{\mathrm{H}}, p$ value of Q-test for heterogeneity test; ${ }^{\mathrm{R}}$ random-effect model; ${ }^{\text {Fixed-effect model. }}$ 


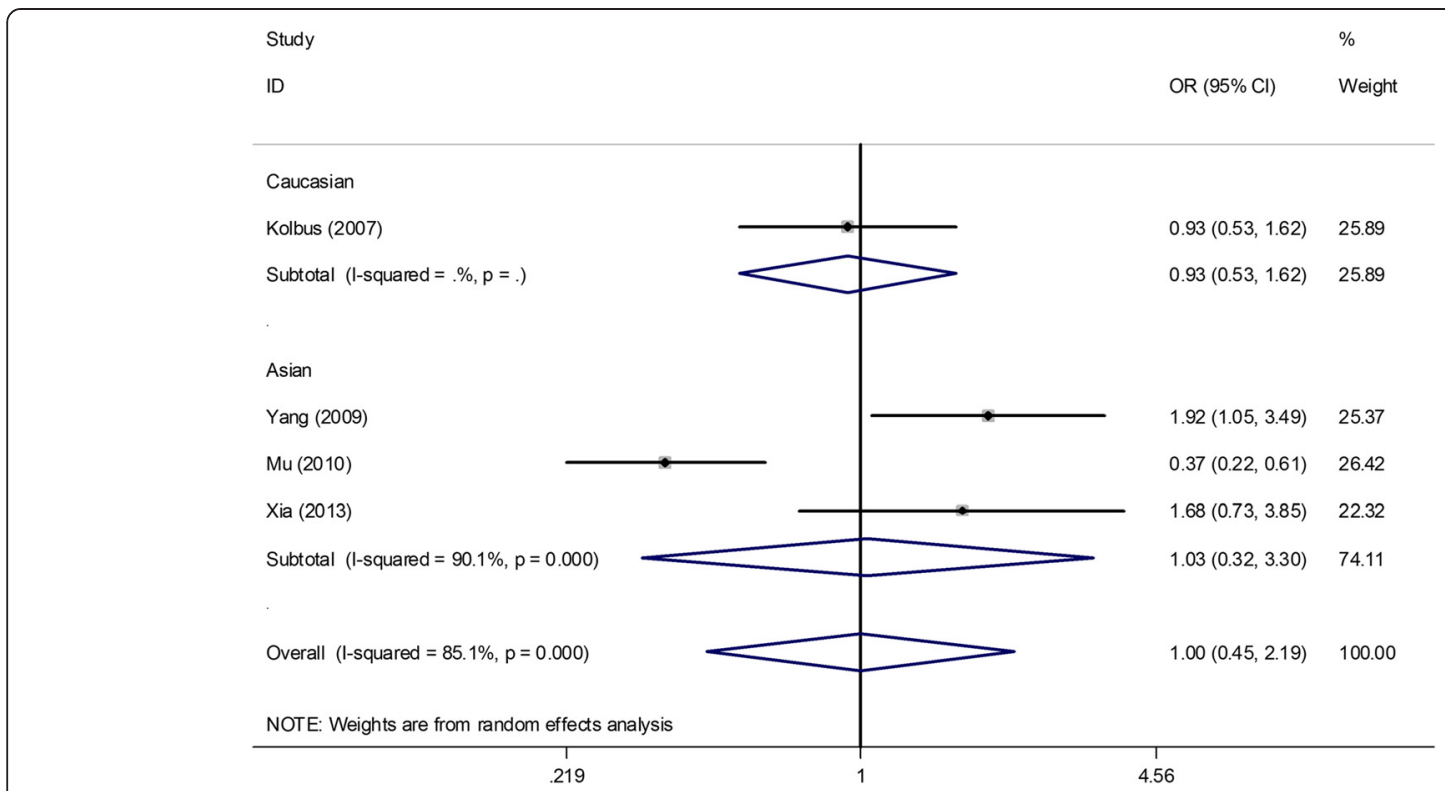

Figure 5 Meta-analysis for the association between the IL-1beta $(-511 \mathrm{C} / T)$ polymorphism and the risk of polycystic ovary syndrome based on the dominant model ( $\mathrm{TT}+\mathrm{CT}$ vs. CC; stratified by ethnicity).

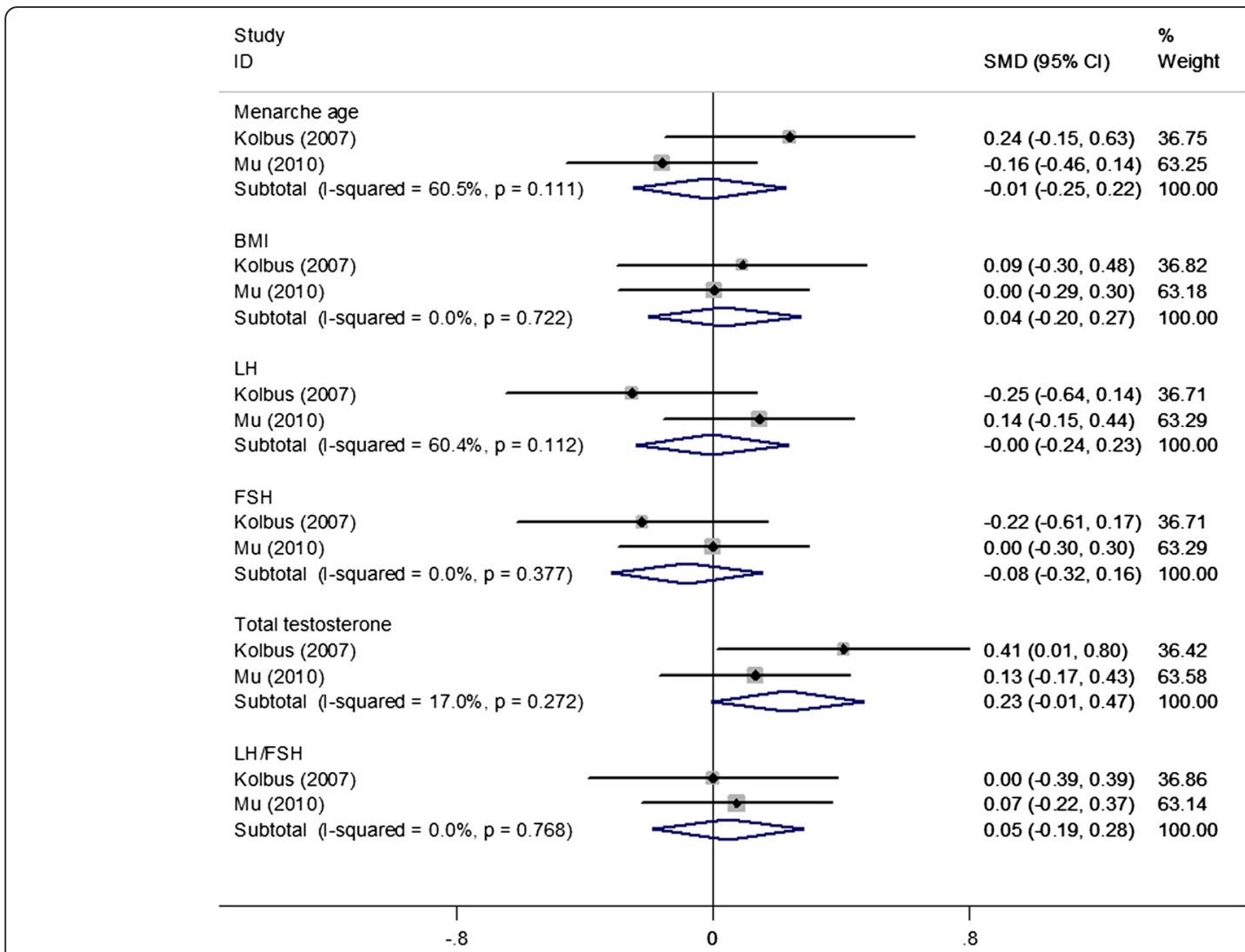

Figure 6 A forest plot for the correlation of the IL-1beta $(-511$ C/T) polymorphism (TT + CT vs. CC) with several clinical and biochemical parameters in patients with polycystic ovary syndrome. 

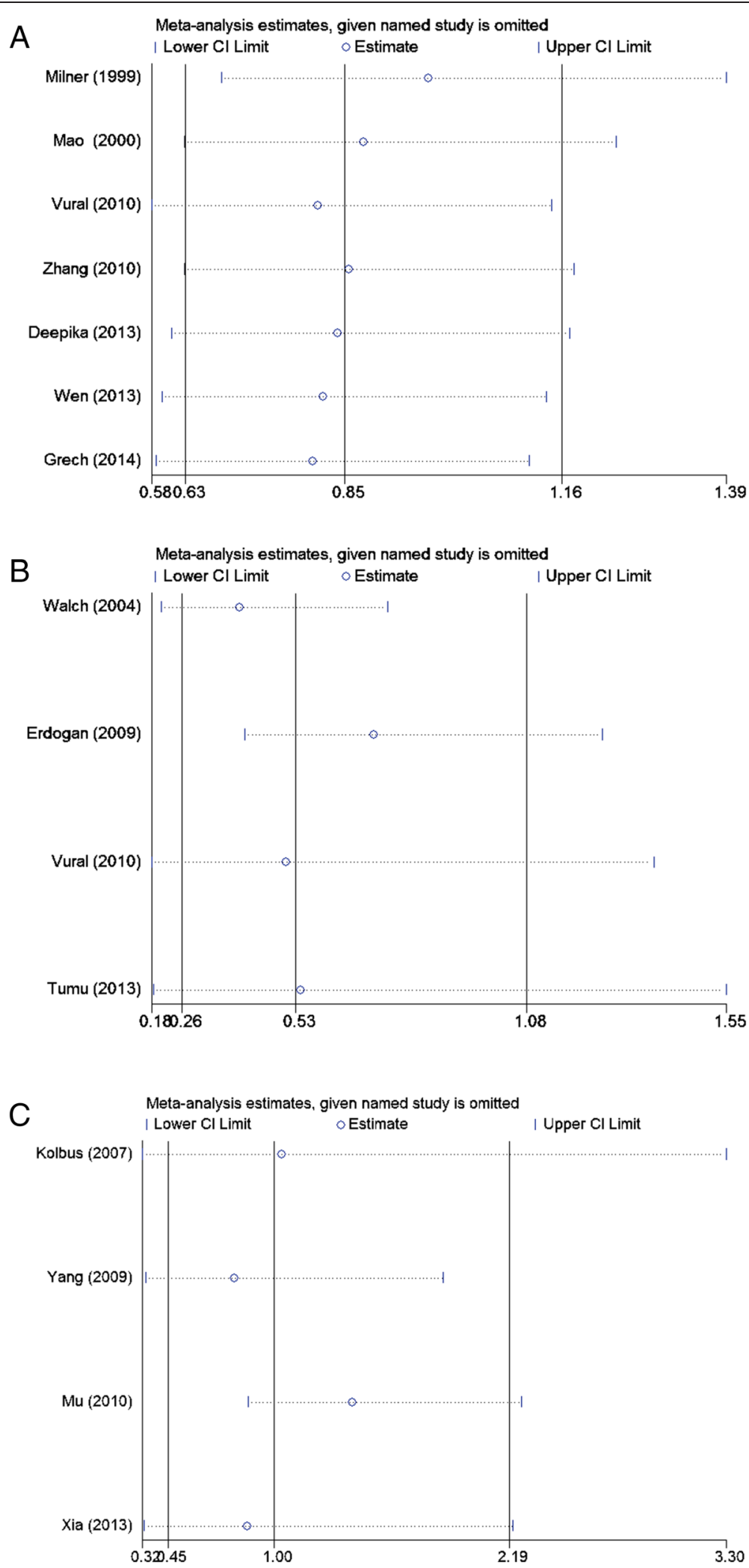

Figure 7 Sensitivity analysis of the summary odds ratio (OR) coefficients on the associations among the TNF-alpha (-308 G/A), IL-6 $(-174 \mathrm{G} / \mathrm{C})$ and IL-1beta $(-511 \mathrm{C} / \mathrm{T})$ polymorphisms with the risk of polycystic ovary syndrome based on the dominant model. (A), TNF-alpha $(-308 \mathrm{G} / \mathrm{A}) ;(\mathbf{B})$, IL-6 (-174 G/C); (C), IL-1beta (-511 C/T). 
Table 5 Statistical analyses of publication bias for TNF-alpha, IL-6 and IL-1beta gene polymorphisms

\begin{tabular}{llllll}
\hline Category & Allele model & Homozygote comparison & Heterozygote comparison & Dominant model & Recessive model \\
\hline TNF-alpha (-308 G/A) & & & & & 0.133 \\
Begg's test & 1.00 & 0.462 & 0.368 & 0.180 & 0.221 \\
Egger's test & 0.704 & 0.732 & 0.190 & 0.616 \\
IL-6 (-174 G/C) & & & 0.734 & 0.734 & 0.734 \\
Begg's test & 0.308 & 1.00 & 0.583 & 0.665 & 0.906 \\
Egger's test & 0.496 & 0.729 & & 0.308 & 0.089 \\
IL-1beta (-511 C/T) & & & 0.734 & 0.346 & 0.178 \\
Begg's test & 0.308 & 0.308 & 0.532 & & \\
Egger's test & 0.023 & 0.089 & & & \\
\hline
\end{tabular}

dysfunction in PCOS [34]. Moreover, variants in genes encoding several proinflammatory cytokines and their receptors associated with obesity, insulin resistance, and diabetes have also been found to be associated with PCOS $[17,35]$. As common multifunctional cytokines, TNF-alpha, IL-6, and IL-1 have been proposed to influence the processes of ovulation, fertilization, and implantation, which are also affected in women with PCOS [36]. However, no significant difference was found by meta-analysis of serum TNF-alpha and IL-6 concentrations in women with PCOS and controls, although only nine studies of TNF-alpha and 10 studies of IL-6 were included [37]. The occurrence of polymorphisms in the TNF-alpha, $I L-6$, and $I L-1$ genes in women affected by PCOS has also been investigated over the past few decades [22,24]. However, due to the relative small sample size, no clear consensus has been reached. The aim of the present study was to perform a metaanalysis of the best evidence available in an attempt to provide high-quality data on the linkage between TNF-alpha (-308 G/A), IL-6 (-174 G/C), and IL-1beta $(-511 \mathrm{C} / \mathrm{T})$ polymorphisms and PCOS risk.

To the best of our knowledge, this is the first meta-analysis concerning TNF-alpha (-308 G/A), IL-6 (-174 G/C), and IL-1beta $(-511 \mathrm{C} / \mathrm{T})$ polymorphisms and PCOS risk. Based on our results, no significant association was found between TNF-alpha (-308 G/A) and IL-1beta (-511 C/T) polymorphisms and PCOS risk in the overall population or subgroup analysis under all genetic models. For the IL-6 (-174 G/C) polymorphism, however, variant $\mathrm{C}$ allele was associated with a lower risk of PCOS in the allelic model ( $\mathrm{C}$ vs. $\mathrm{G}$ : $\mathrm{OR}=0.63,95 \% \mathrm{CI}=0.41-0.96$ ) and by homozygote comparison (CC vs. GG: OR $=0.52,95 \%$ $\mathrm{CI}=0.30-0.93)$, even though the $p$-value $(0.032$ and 0.042 , respectively) was marginal. Our results indicate that the IL-6 (-174 G/C) polymorphism likely conveys a protective effect against PCOS. A possible explanation for this finding is that the $I L-6 \mathrm{C}$ allele results in low IL- 6 production, which may normalize ovarian function. However, the results of this meta-analysis should be cautiously interpreted. First, in the subgroup analysis, no association was found between the $I L-6(-174 \mathrm{G} / \mathrm{C})$ polymorphism and PCOS risk by the genotyping method of pyrosequencing in any genetic model. Although the $I L-6(-174 \mathrm{G} / \mathrm{C})$ polymorphism was associated with PCOS in Caucasian populations and in the subgroup analysis of PCR-RFLP genotyping method, one study [21] showed deviations in genotype frequency from the HWE of controls. Second, after excluding two studies with deviations from the HWE in controls $[21,23]$, which had a sample size of $>200$, the result showed that the $I L-6(-174 \mathrm{G} / \mathrm{C})$ polymorphism was no longer associated with PCOS. Although the relatively limited study number (only two studies for IL-6 (-174 G/C) polymorphism in the subgroup analysis specific to HWE in controls and genotyping method of pyrosequencing) and small sample size might have resulted in the null results, we could not rule out the possibility that the $I L-6$ $(-174 \mathrm{G} / \mathrm{C})$ polymorphism was actually not associated with PCOS risk. Our overall positive results might be dominated by the studies showing deviation from the HWE in controls. No heterogeneity was observed for the TNF-alpha (-308 G/A) polymorphism. For the IL-6 $(-174 \mathrm{G} / \mathrm{C})$ and IL-1beta $(-511 \mathrm{C} / \mathrm{T})$ polymorphisms, however, there was significant heterogeneity in the overall population and in the subgroup of HWE in controls, ethnicity, genotyping method, and sample size that might have influenced the results. Sensitivity analysis was then conducted, which confirmed the stability and reliability of our results.

The pooled results also demonstrated that there was no obvious association of the TNF-alpha (-308 G/A) polymorphism with obesity, or between the $I L$-1beta $(-511 \mathrm{C} / \mathrm{T})$ polymorphism with several clinical and biochemical parameters, in patients with PCOS. However, It should be noted that not all studies evaluated the effect of interactions, with two studies $[17,26]$ providing complete data on different genetic models and three $[15,16,24]$ just presenting data on the dominant model. Furthermore, other clinical and laboratory characteristics (including metabolic parameters and androgen parameters) according to the genotypes of TNF-alpha (-308 G/A), IL-6 
(-174 G/C), and IL-1beta (-511 C/T) polymorphisms in the PCOS patients and the control group could not evaluated due to a lack of sufficient data. Therefore, our results, which only presented data on the dominant model of the TNF-alpha (-308 G/A) and IL-1beta (-511 C/T) polymorphisms, should be interpreted with caution. Insulin resistance and hyperinsulinemia are the central features of the metabolic disturbances typical for PCOS [37]. The TNF-alpha (-308 G/A) polymorphism was reported to be associated with altered responses to oral glucose tolerance testing in the PCOS group [14]. TNF-alpha is over-expressed in the adipose tissue of obese subjects in proportion to the degree of insulin resistance [38]. The $I L-6$ polymorphism investigated in this study was shown to be associated with lipid abnormalities and impaired insulin sensitivity $[39,40]$. IL-1beta was proposed as a promoter of nitrogen (NO) generation and apoptosis of pancreatic islet $B$ cell, which also induced insulin resistance [26]. However, a study by Puder et al. showed that an increase in both low-grade chronic inflammation and insulin resistance in PCOS patients is associated with increased central fat excess rather than PCOS status [41]. It remains to be established whether the proinflammatory state in PCOS is primarily a result of genetic variation or simply inflamed adipose tissue, because there is an increased prevalence of abdominal adiposity in PCOS across all weight classes. In fact, no differences were reported in levels of TNF-alpha, IL-6, and markers of inflammation between obese women with PCOS and obese controls [42]. A study by Mohlig et al. also showed that plasma levels of IL-6 and C-reactive protein were not increased in women with PCOS when compared to controls matched by age and BMI [43]. Previous studies have proposed that polymorphisms to the TNF-alpha (-308 G/A) and IL-1beta $(-511 \mathrm{C} / \mathrm{T})$ genes might be the genetic basis for the increase in TNF-alpha and IL-1beta serum levels in patients with PCOS $[7,24]$. Regarding the $I L-6(-174 \mathrm{G} / \mathrm{C})$ polymorphism, however, several investigations have reported that the homozygous CC genotype was associated with higher serum IL-6 levels, which is in contrast to studies indicating that the G allele is associated with increased IL-6 secretion in subjects with PCOS, metabolic syndrome, and insulin resistance $[12,22,39,44]$. It appears that transcriptional control of IL-6 is multifaceted and may be dependent on the impact of other sites of polymorphisms which may be in linkage disequilibrium with the $I L-6$ gene locus [45]. Furthermore, it has been suggested that obesity-associated genes, environmental factors, and gene-environment interactions, as well as dietary habits are also responsible for the increasing prevalence of PCOS worldwide [17,46,47].

Several limitations to this study need to be taken into account when interpreting our results. First, the number of study and the sample sizes were relatively small for analysis of each gene polymorphism thereby having insufficient power to detect any true difference between cases and controls. Second, heterogeneity was detected in the IL-1beta $(-511 \mathrm{C} / \mathrm{T})$ polymorphisms and the source of heterogeneity could not be identified due to the limited number of studies included in each pooled outcome. Third, the results of our meta-analysis were not adjusted for confounding factors, such as age and BMI, due to the lack of sufficient data, which might have influenced the effect estimates. Finally, the etiology of PCOS has long been described as multifactorial; however, it was difficult for us to analyze interactions between genes, lifestyles, and certain environmental factors.

\section{Conclusions}

In summary, the results of this meta-analysis suggested that variations of the TNF-alpha (-308 G/A), IL-6 $(-174 \mathrm{G} / \mathrm{C})$, and IL-1beta $(-511 \mathrm{C} / \mathrm{T})$ genes might not represent genetic risk factors for PCOS. However, there is a need for further larger-scale studies, including other loci of the TNF-alpha, IL-6, and IL-1beta genes, to confirm our results and elucidate the potential association and influence of cytokine gene polymorphisms, and gene-environment interactions on the development of PCOS.

\section{Additional file}

Additional file 1: Prisma checklist.

\section{Abbreviations}

BMI: Body mass index; Cl: Confidence interval; HWE: Hardy-Weinberg equilibrium; IL: Interleukin; OR: Odds ratio; $p$ : Probability; PCOS: Polycystic ovary syndrome; PRISMA: The preferred reporting items for systematic reviews and meta-analysis; SNP: Single nucleotide polymorphism; TNF-alpha: Tumor necrosis factor alpha; vs.: Versus.

\section{Competing interests}

The authors declare that they have no competing interests.

\section{Authors' contributions}

RYG and NNZ conceived and designed the experiments. YZ and NNZ extracted the data and conducted the experiment. $Y Z$ and $Z Z Y$ assessed the quality of studies and analyzed the data. RYG and YZ wrote the manuscript. All authors read and approved the final manuscript.

\section{Acknowledgements}

This work was financially supported by grants from the Zhejiang Medical Health Fund of China (grant No.: 2012RCA020) and the National High-technology R\&D Program of China (grant No.: 2013CB531406).

\section{Author details}

'Department of Laboratory Medicine, First Affiliated Hospital, College of Medicine, Zhejiang University, Hangzhou, Zhejiang 310003, China.

2Department of Gynecology and Obstetrics, Tongde Hospital of Zhejiang Province, Hangzhou, Zhejiang 310012, China. ${ }^{3}$ State Key Laboratory for Diagnosis and Treatment of Infectious Disease, First Affiliated Hospital, College of Medicine, Zhejiang University, Hangzhou 310003, China.

Received: 12 October 2014 Accepted: 16 January 2015

Published online: 30 January 2015 


\section{References}

1. Azziz R, Woods KS, Reyna R, Key TJ, Knochenhauer ES, Yildiz BO. The prevalence and features of the polycystic ovary syndrome in an unselected population. J Clin Endocrinol Metab. 2004:89:2745-9.

2. Goodarzi MO, Dumesic DA, Chazenbalk G, Azziz R. Polycystic ovary syndrome: etiology, pathogenesis and diagnosis. Nat Rev Endocrinol. 2011;7:219-31

3. Diamanti-Kandarakis E, Piperi C, Spina J, Argyrakopoulou G, Papanastasiou L, Bergiele A, et al. Polycystic ovary syndrome: the influence of environmental and genetic factors. Hormones (Athens). 2006:5:17-34.

4. Deligeoroglou E, Vrachnis N, Athanasopoulos N, Iliodromiti Z, Sifakis S, Iliodromiti $\mathrm{S}$, et al. Mediators of chronic inflammation in polycystic ovarian syndrome. Gynecol Endocrinol. 2012;28:974-8.

5. Escobar-Morreale HF, Calvo RM, Sancho J, San Millan JL. TNF-alpha and hyperandrogenism: a clinical, biochemical, and molecular genetic study. J Clin Endocrinol Metab. 2001;86:3761-7.

6. Vgontzas AN, Trakada G, Bixler EO, Lin HM, Pejovic S, Zoumakis E, et al. Plasma interleukin 6 levels are elevated in polycystic ovary syndrome independently of obesity or sleep apnea. Metabolism. 2006;55:1076-82.

7. Xia YH, Yao L, Zhang ZX. Correlation between IL-1 $\beta$, IL-1Ra gene polymorphism and occurrence of polycystic ovary syndrome infertility. Asian Pac J Trop Med. 2013;6:232-6.

8. Brannstrom M, Friden $\mathrm{BE}$, Jasper $\mathrm{M}$, Norman RJ. Variations in peripheral blood levels of immunoreactive tumor necrosis factor alpha (TNFalpha) throughout the menstrual cycle and secretion of TNFalpha from the human corpus luteum. Eur J Obstet Gynecol Reprod Biol. 1999;83:213-7.

9. Deshpande RR, Chang MY, Chapman JC, Michael SD. Alteration of cytokine production in follicular cystic ovaries induced in mice by neonatal estradiol injection. Am J Reprod Immunol. 2000;44:80-8.

10. Sukhikh GT, Vanko LV. Interrelationships between Immune and Reproductive Systems in Human. Russ J Immunol. 1999;4:312-4.

11. Baghel K, Srivastava RN, Chandra A, Goel SK, Agrawal J, Kazmi HR, et al. TNF-alpha, IL-6, and IL-8 cytokines and their association with TNF-alpha-308 G/A polymorphism and postoperative sepsis. J Gastrointest Surg. 2014;18:1486-94.

12. Fishman D, Faulds G, Jeffery R, Mohamed-Ali V, Yudkin JS, Humphries S, et al. The effect of novel polymorphisms in the interleukin-6 (IL-6) gene on IL-6 transcription and plasma IL-6 levels, and an association with systemic-onset juvenile chronic arthritis. J Clin Invest. 1998;102:1369-76.

13. Dundar NO, Aktekin B, Ekinci NC, Sahinturk D, Yavuzer U, Yegin O, et al. Interleukin-1 beta secretion in hippocampal sclerosis patients with mesial temporal lobe epilepsy. Neurol Int. 2013:5:e17.

14. Milner CR, Craig JE, Hussey ND, Norman RJ. No association between the -308 polymorphism in the tumour necrosis factor alpha (TNFalpha) promoter region and polycystic ovaries. Mol Hum Reprod. 1999;5:5-9.

15. Mao WW, Yu L, Chen YJ, Zhang XW, Li MZ. Study on the relationship between a polymorphism of tumor necrosis factor-a gene and the pathogenesis of polycystic ovary syndrome. Chin J Obstet Gynecol. 2000;2000:536-9.

16. Zhang J, Liu Q. Association study of genetic polymorphisms in LEP and TNFa genes with the pathogenesis of polycystic ovary syndrome. Chin J Heath Lab Technol. 2010;20:3272-4.

17. Deepika ML, Reddy KR, Yashwanth A, Rani VU, Latha KP, Jahan P. TNF-alpha haplotype association with polycystic ovary syndrome - a South Indian study. J Assist Reprod Genet. 2013;30:1493-503.

18. Wen Q, Wu J, Wu LY, Liu LJ, Yang HB, Sun ZX, et al. Association of TNF-a G-308A and G-238A gene polymorphisms with PCOS in women. Chin J Clin. 2013;7:3394-9.

19. Grech I, Giatrakos S, Damoraki G, Kaldrimidis P, Rigopoulos D, GiamarellosBourboulis EJ. Impact of TNF haplotypes in the physical course of acne vulgaris. Dermatology. 2014;228:152-7.

20. Walch K, Grimm C, Zeillinger R, Huber JC, Nagele F, Hefler LA. A common interleukin-6 gene promoter polymorphism influences the clinical characteristics of women with polycystic ovary syndrome. Fertil Steril. 2004;81:1638-41.

21. Erdogan M, Karadeniz M, Berdeli A, Tamsel S, Yilmaz C. The relationship of the interleukin-6-174 G > C gene polymorphism with cardiovascular risk factors in Turkish polycystic ovary syndrome patients. Int J Immunogenet. 2009;36:283-8

22. Vural P, Degirmencioglu S, Saral NY, Akgul C. Tumor necrosis factor alpha (-308), interleukin-6 (-174) and interleukin-10 (-1082) gene polymorphisms in polycystic ovary syndrome. Eur J Obstet Gynecol Reprod Biol. 2010;150:61-5.

23. Tumu VR, Govatati S, Guruvaiah P, Deenadayal M, Shivaji S, Bhanoori M. An interleukin-6 gene promoter polymorphism is associated with polycystic ovary syndrome in South Indian women. J Assist Reprod Genet. 2013;30:1541-6.

24. Kolbus A, Walch K, Nagele F, Wenzl R, Unfried G, Huber JC. Interleukin-1 alpha but not interleukin-1 beta gene polymorphism is associated with polycystic ovary syndrome. J Reprod Immunol. 2007;73:188-93.

25. Yang Y, Qiao J, Tang RX, Li MZ. Genotype and haplotype determination of interleukin (IL) 1 beta (g. $-511 \mathrm{C}>\mathrm{T}$ and g. $+3954 \mathrm{C}>\mathrm{T}$ ) and IL-1RN in polycystic ovary syndrome. Fertil Steril. 2010;94:384-6.

26. Mu Y, Liu J, Wang B, Wen Q, Wang J, Yan J, et al. Interleukin 1 beta (IL-1beta) promoter C [-511] T polymorphism but not C [+3953] T polymorphism is associated with polycystic ovary syndrome. Endocrine. 2010;37:71-5.

27. Moher D, Liberati A, Tetzlaff J, Altman DG, Group P. Preferred reporting items for systematic reviews and meta-analyses: the PRISMA statement. PLoS Med. 2009;6:e1000097.

28. Yang B, Fan S, Zhi X, Li Y, Liu Y, Wang D, et al. Associations of MTHFR gene polymorphisms with hypertension and hypertension in pregnancy: a meta-analysis from 114 studies with 15411 cases and 21970 controls. PLoS One. 2014;9:e87497.

29. Higgins JP, Thompson SG, Deeks JJ, Altman DG. Measuring inconsistency in meta-analyses. BMJ. 2003:327:557-60.

30. DerSimonian R, Laird N. Meta-analysis in clinical trials. Control Clin Trials. 1986:7:177-88.

31. Mantel N, Haenszel W. Statistical aspects of the analysis of data from retrospective studies of disease. J Natl Cancer Inst. 1959:22:719-48.

32. Begg CB, Mazumdar M. Operating characteristics of a rank correlation test for publication bias. Biometrics. 1994;50:1088-101.

33. Egger M, Davey Smith G, Schneider M, Minder C. Bias in meta-analysis detected by a simple, graphical test. BMJ. 1997;315:629-34.

34. Gonzalez F, Rote NS, Minium J, Kirwan JP. Increased activation of nuclea factor kappaB triggers inflammation and insulin resistance in polycystic ovary syndrome. J Clin Endocrinol Metab. 2006;91:1508-12.

35. Repaci A, Gambineri A, Pasquali R. The role of low-grade inflammation in the polycystic ovary syndrome. Mol Cell Endocrinol. 2011;335:30-41.

36. Gonzalez F. Inflammation in Polycystic Ovary Syndrome: underpinning of insulin resistance and ovarian dysfunction. Steroids. 2012;77:300-5.

37. Escobar-Morreale HF, Luque-Ramirez M, Gonzalez F. Circulating inflammatory markers in polycystic ovary syndrome: a systematic review and meta-analysis. Fertil Steril. 2011;95:1048-58.

38. Kubaszek A, Pihlajamaki J, Komarovski V, Lindi V, Lindstrom J, Eriksson J, et al. Promoter polymorphisms of the TNF-alpha (G-308A) and IL-6 (C-174G) genes predict the conversion from impaired glucose tolerance to type 2 diabetes: the Finnish Diabetes Prevention Study. Diabetes. 2003;52:1872-6

39. Fernandez-Real JM, Broch M, Vendrell J, Richart C, Ricart W. Interleukin-6 gene polymorphism and lipid abnormalities in healthy subjects. J Clin Endocrinol Metab. 2000;85:1334-9.

40. Fernandez-Real JM, Broch M, Vendrell J, Gutierrez C, Casamitjana R, Pugeat $M$, et al. Interleukin-6 gene polymorphism and insulin sensitivity. Diabetes. 2000;49:517-20

41. Puder JJ, Varga S, Kraenzlin M, De Geyter C, Keller U, Muller B. Central fat excess in polycystic ovary syndrome: relation to low-grade inflammation and insulin resistance. J Clin Endocrinol Metab. 2005;90:6014-21.

42. Sathyapalan T, Atkin SL. Mediators of inflammation in polycystic ovary syndrome in relation to adiposity. Mediators Inflamm. 2010:2010:758656

43. Mohlig M, Spranger J, Osterhoff M, Ristow M, Pfeiffer AF, Schill T, et al. The polycystic ovary syndrome per se is not associated with increased chronic inflammation. Eur J Endocrinol. 2004;150:525-32.

44. Jerrard-Dunne P, Sitzer M, Risley P, Steckel DA, Buehler A, von Kegler S, et al. Interleukin- 6 promoter polymorphism modulates the effects of heavy alcohol consumption on early carotid artery atherosclerosis: the Carotid Atherosclerosis Progression Study (CAPS). Stroke. 2003:34:402-7.

45. Terry CF, Loukaci V, Green FR. Cooperative influence of genetic polymorphisms on interleukin 6 transcriptional regulation. J Biol Chem. 2000:275:18138-44. 
46. Carroll J, Saxena R, Welt CK. Environmental and genetic factors influence age at menarche in women with polycystic ovary syndrome. J Pediatr Endocrinol Metab. 2012;25:459-66.

47. Deligeoroglou E, Kouskouti C, Christopoulos P. The role of genes in the polycystic ovary syndrome: predisposition and mechanisms. Gynecol Endocrinol. 2009;25:603-9.

Submit your next manuscript to BioMed Central and take full advantage of:

- Convenient online submission

- Thorough peer review

- No space constraints or color figure charges

- Immediate publication on acceptance

- Inclusion in PubMed, CAS, Scopus and Google Scholar

- Research which is freely available for redistribution 